\title{
Last Concentration Normalized by Dose
}

National Cancer Institute

\section{Source}

National Cancer Institute. Last Concentration Normalized by Dose. NCI Thesaurus. Code C92388.

The concentration corresponding to Tlast divided by the dose. 